\title{
Desafios DA AUTONOMIZAÇÃO: ESTUDO DAS TRANSIÇÓES SEGUNDO JOVENS ADULTOS EX-INSTITUCIONALIZADOS
}

\author{
EMPOWERMENT CHALLENGES: STUDY OF TRANSITION \\ BY EX-INSTITUTIONALIZED YOUNG ADULTS
}

DESAFIOOS DE EMPODERAMIENTO: ESTUDIO DE LAS TRANSICIONES SEGÚN JÓVENES EX-INSTITUCIONALIZADOS

\author{
João Pedro M. Gaspar* \\ Eduardo J. R. Santos** \\ Joaquim Luis M. Alcoforado***
}

\section{RESUMo}

Este artigo dá conta de uma investigação centrada nas transiçóes de jovens adultos que viveram um longo período das suas vidas em instituiçóes de acolhimento para crianças e jovens - Lares de Infância e Juventude - e estáo agora autonomizados. A estrutura pretende articular a teoria ecológica do desenvolvimento humano de Bronfenbrenner com modelos de transiçóes (com especial incidência em Schlossberg), majorando a influência das vinculações criadas por crianças e jovens institucionalizados com cuidadores e entre os pares; visa fundamentar a metodologia utilizada na recolha e validação das entrevistas biográficas, enquadrando o trabalho em duas instituiçóes da regiāo Centro de Portugal, caracterizando o seu funcionamento; incide sobre a descrição, na perspetiva de adultos e jovens adultos ex-institucionalizados, das transiçóes ao longo dos diversos espaços e tempos das suas vidas, nomeadamente através da sua perceção dos momentos de vida mais marcantes, das vinculaçóes estabelecidas e da sua importância para aumentar a resiliência e competir para a sua integração social. Pretende-se assim compreender a perceção que os ex-utentes têm da relação entre o apoio e a formação que lhes foi proporcionada enquanto institucionalizados e o eventual contributo desses adquiridos na sua posterior integração nos diferentes contextos de vida.

Palavras-chave: transiçôes; vinculação; autonomização; crianças e jovens institucionalizados.

* Universidade de Coimbra, Coimbra, Portugal.

** Universidade de Coimbra, Coimbra, Portugal.

*** Universidade de Coimbra, Coimbra, Portugal. 


\section{Abstract}

This paper presents a research, focusing on transitions of young adults who lived in institutions for children and young people who are now independent. It which designed to articulate Bronfenbrenner's ecological theory of human development with models of transitions (particular focus on Schlossberg), subsequently adding the influence of the linkages created by institutionalized children and youth; which aims to support the methodology used in the collection and validation of biographical interviews, framing the work in monitoring and education and training activities carried out in two institutions in the region of Central Portugal; focuses on the description in perspective of ex-institutionalized adult and young adult transitions over the various spaces and times of their lives, particularly through their perception of the salient moments of life and established attachments.

Keywords: transitions; attachment; empowerment; institutionalized children and youngsters.

\section{RESUMEN}

Este artículo da a conocer una investigación aún en curso centrada en las transiciones de adultos e jóvenes que han vivido en instituciones de acogimiento de niños y jóvenes que están ahora a vivir de manera independiente. Su estructura pretende articular la teoría ecológica del desarrollo humano de Bronfenbrenner con modelos de transiciones (particular énfasis en Schlossberg) dando privilegio a la influencia de los vínculos creados por niños y jóvenes que viven en instituciones; pretende fundamentarse la metodología utilizada, en la recolección y validación de las entrevistas biográficas, encuadrando el trabajo en el acompañamiento y actividades de educación y formación desarrolladas en dos instituciones situadas en la región Central de Portugal; incide en la descripción en la perspectiva de los adultos y jóvenes adultos ex-institucionalizados, de las transiciones a lo largo de los diferentes espacios y tiempos de sus vidas, sobre todo a través de su percepción de los momentos de vida que sobresalen y de las vinculaciones establecidas. Para la consecución de este último nivel se realizaran entrevistas de cuño biográfico que visaran identificar las percepciones de los intervinientes acerca de la influencia de su institucionalización en su vida autónoma.

Palabras clave: transiciones; enlace; empoderamiento; niños e jóvenes institucionalizados. 
São meus discípulos, se alguns tenho, os que estão contra mim; porque esses guardaram no fundo da alma a força que verdadeiramente me anima e que mais desejaria transmitir-lhes: a de não se conformarem. Professor Agostinho da Silva

\section{Introdução}

A transversalidade da educação torna-se crucial ao conceber procedimentos facilitadores da inclusão de menores que passaram uma fase importante da vida em Lares de Acolhimento. Este estudo visa compreender condicionantes do acolhimento que interferem no desenvolvimento ecológico e nas vinculaçôes desses jovens, proporcionando-lhes transiçôes favoráveis à sua integração na sociedade.

Salienta-se o carácter exploratório desta investigação ${ }^{1}$, que incide sobre os desafios da autonomização, através de um estudo compreensivo dos processos de transição para diferentes contextos de vida, na perspetiva de adultos e jovens adultos ex-institucionalizados.

Para atingir os objetivos propostos, este trabalho teve por base uma metodologia qualitativa baseada, predominantemente, em entrevistas aprofundadas, proporcionadoras de descrições detalhadas das diferentes experiências pessoais e sociais, destacando os momentos de vida marcantes a ex-acolhidos de dois Lares de Infância e Juventude (LIJ). Pretende-se assim compreender a perceçáo que têm das vivências proporcionadas enquanto institucionalizados, com especial incidência nas afiliações desenvolvidas e o eventual contributo desses adquiridos na sua posterior integração nos diferentes contextos de vida.

A escassa literatura sobre autonomização e transiçóes de adultos e jovens adultos que viveram longos períodos em lares de acolhimento, sobretudo com base na sua perspetiva pessoal, contrasta com o crescente interesse pela temática que abrange crianças e adolescentes institucionalizados que se tem verificado ultimamente.

Em Portugal são conhecidos poucos estudos que tentem aferir a influência da institucionalização no funcionamento socioemocional em menores acolhidos, destacando um divulgado parcialmente em 2012 e resultante de uma investigação que envolveu 85 crianças com idades entre os 12 e os 30 meses de idade, aos cuidados de 19 centros de acolhimento, que revela a dificuldade que crianças institucionalizadas têm em criar laços afetivos com quem cuida delas, apontan- 
do que mais de metade das crianças institucionalizadas exibe padróes atípicos de vinculação, apresentando dificuldades na criação de laços com os cuidadores institucionais (I. Soares, J. Baptista, S. Marques, \& J. Silva, 2012 - comunicação pessoal).

Outro estudo exploratório, apresentado em 2009, examinou o desenvolvimento mental e a qualidade do funcionamento socioemocional de 16 crianças entre os 3 e os 6 anos, institucionalizadas em Centros de Acolhimento Temporário, relacionando-os com a qualidade das narrativas sobre o apego das suas cuidadoras, e os resultados sugerem que o nível de desenvolvimento mental se situou abaixo dos valores normativos, ou seja, os dados encontrados parecem ser consistentes com o impacto negativo do fenómeno da privação dos cuidados parentais em meio institucional (Pereira, 2010).

Embora sejam estudos com crianças, parece pacífico considerar que os resultados se refletirão ao longo da vida dos indivíduos que viveram institucionalizaçóes precoces e longas. De resto, segundo uma investigadora comum aos dois trabalhos, "quanto maior for o tempo de institucionalização, mais nefastas serão as suas implicações no desenvolvimento emocional, cognitivo, social e académico destas crianças” (I. Soares, J. Baptista, S. Marques, \& J. Silva, 2012 - comunicação pessoal). Aliás, estudos realizados por Ainsworth mostram que a noção de figura de vinculação pode tornar-se um marco para o desenvolvimento da criança, enquanto futuro adolescente e adulto (Ainsworth, 1977).

Em 2011 havia 8.938 menores acolhidos e 36.709 processos ativos nas Comissóes de Proteção de Crianças e Jovens (CPCJ), constituindo uma franja razoável da população jovem portuguesa (Gaspar, 2013). Sendo o número de acolhidos em Lares de Infância e Juventude claramente superior aos restantes menores em outras respostas sociais, fará sentido estudar a realidade mais abrangente desta problemática, atendendo igualmente ao facto da autonomização ser o destino mais recorrente.

Reportando-nos às vivências dos participantes, seria importante tentar aferir de que modo as afiliaçóes desenvolvidas antes, mas sobretudo no período de institucionalização, foram determinantes como interaçóes seguras na perspetiva da teoria ecológica do desenvolvimento humano. No fundo, perceber como a institucionalização pode ser um fator positivo ou negativo nas transições que já vivenciaram e na preparação para a vida adulta - autonomização, nas suas perspetivas de adultos e jovens adultos.

De acordo com a Teoria Bioecológica do Desenvolvimento Humano (Bronfenbrenner, 1979/2004; Bronfenbrenner \& Morris, 1998), além do contexto, o processo é o principal responsável pelo desenvolvimento ocorrido. Ou 
seja, o facto de alguém crescer num lar de acolhimento para menores não pode à partida ser entendido como risco ou proteção, dependendo mais da qualidade das relaçóes e da presença de afetividade e reciprocidade que a institucionalização proporcionar.

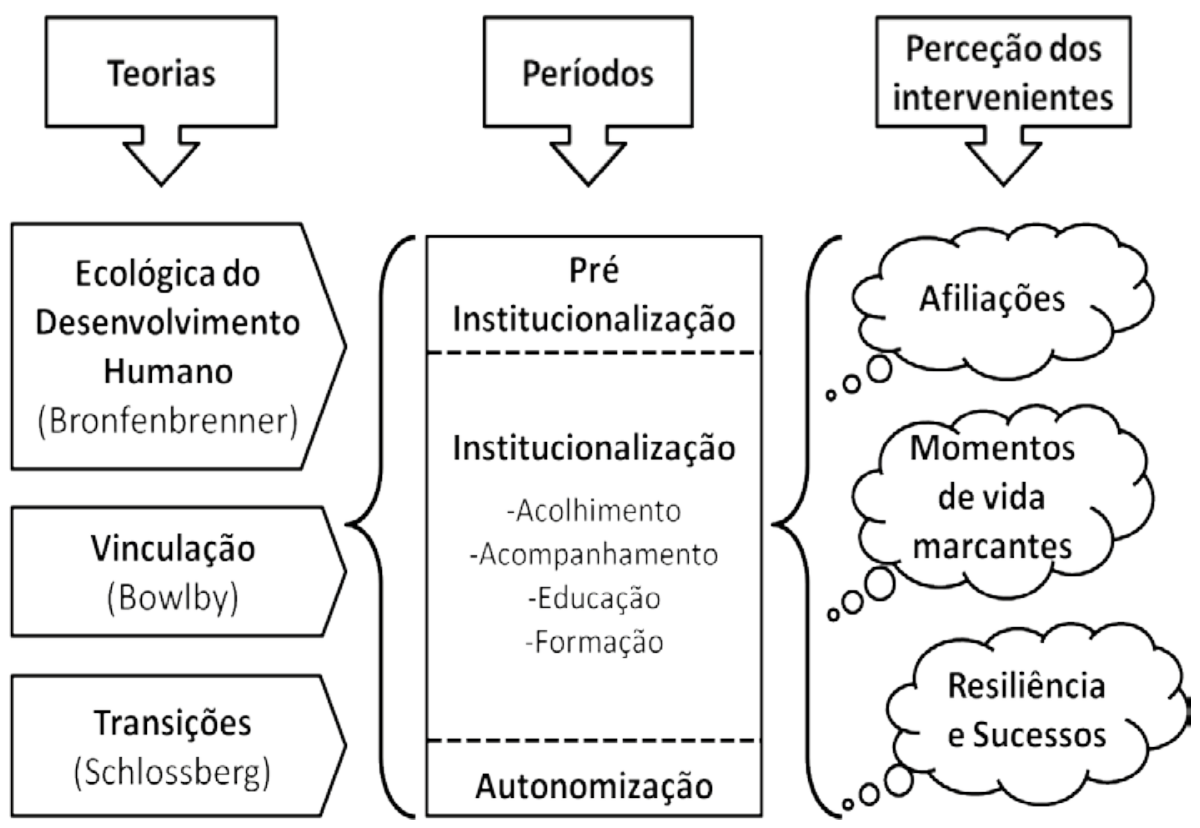

Figura 1. Esquema conceptual da investigação

Estarão os menores acolhidos disponíveis para estabelecer ligações afetivas? Como se poderá facilitar a reestruturação da vinculação nestes jovens? Qual a sua perceção?

\section{Modelos teóricos}

São vários os autores que desenvolveram teorias aplicáveis a menores institucionalizados. Para este estudo foram levados em particular consideração a teoria ecológica do desenvolvimento humano de Bronfenbrenner, a teoria da vinculação de Bowlby e o estudo das transiçóes de Schlossberg. 


\section{Teoria ecológica do desenvolvimento humano}

Compreender as transiçóes de adultos e jovens adultos que viveram em lares de acolhimento não se pode dissociar de investigar ecologicamente o desenvolvimento deles enquanto crianças e adolescentes institucionalizados, ou, segundo Bronfenbrenner (1979/2004), entendê-los como "pessoas em desenvolvimento" e considerar este desenvolvimento "no contexto".

$\mathrm{Na}$ tentativa de compreensão das conexóes entre as principais esferas de desenvolvimento (família, escola, instituição), surge como uma referência o modelo ecológico de Bronfenbrenner (1979/2004) ou, mais recentemente denominado, modelo bioecológico (Bronfenbrenner \& Morris, 1998), que considera o desenvolvimento de forma vasta, focalizando-se nas interaçóes das pessoas nos seus distintos contextos de vida.

\section{Teoria da vinculação}

As interaçóes, tão importantes na teoria ecológica do desenvolvimento humano, carecem de ser marcadas por sentimentos afetivos positivos; logo, só podem ocorrer de uma forma segura se a afiliação for uma realidade, pois, sendo esta a necessidade que o ser humano tem de se relacionar com as outras pessoas, é também uma estratégia que nos permite manter algum equilíbrio nas vivências sociais.

Os relacionamentos de proximidade e entrega desenvolvidos nos lares de acolhimento desencadeiam processos que podem favorecer o desenvolvimento da competência e do carácter, podendo influenciar a trajetória de vida dos indivíduos de forma a inibir ou incentivar a expressão de competências cognitivas, sociais e emocionais.

Para a maioria dos menores em acolhimento, os lares representam o ambiente próximo de maior impacto nas suas vidas, no fundo um microssistema coberto de atividades, papéis e interaçóes simbólicas. Mas a simples ausência de interaçôes com um ou mais adultos que queiram o bem incondicional destas crianças e adolescentes, que estáo sob os seus cuidados, pode configurar uma ameaça ao desenvolvimento psicológico sadio (Yunes, Miranda, \& Cuello, 2004).

A entrada na instituição pode ser vivida como um castigo ou rejeição pela família. Esta, ainda que problemática, veicula nas crianças um sentido de pertença, ao contrário da instituição que em muitos casos é vista como um último recurso, criando uma sensaçẫo de clausura num local onde não escolheram estar. À luz de uma perspetiva de vinculação, o processo de institucionalização é 
acompanhado de sentimentos de perda, abandono e solidão, na medida em que implica o confronto com a realidade de negligência e insensibilidade parental. A perda traduz-se na quebra nos laços afetivos que se avista temerosa por parte dos jovens (Strecht, 1998).

A teoria da vinculação (Bowlby, 1969) defende que, usando normalmente os exemplos das pessoas que nos estáo mais próximas, criamos importantes referenciais humanos de comportamento que nos passam as noçóes de bem e mal, correto e incorreto e todas as outras relacionadas com açóes comportamentais. Nas crianças e jovens institucionalizados, a perda de uma dessas referências pode desequilibrar ainda mais aspetos importantes das vivências sociais.

As principais necessidades afiliativas são a vinculação, a integração social, a certeza restabelecida de valor, o sentimento de aliança consistente, a obtenção de encaminhamento e a oportunidade de educação, pois, apesar de a vinculação estar relacionada com uma necessidade biológica do ser humano, a escolha das figuras referenciais está relacionada com a necessidade de segurança emocional e proteção. Esta necessidade irá durar ao longo da vida, pois, durante a sua existência e nas novas vivências, as pessoas têm necessidade de sentir um ponto de conforto, uma base segura (Ainsworth, 1989) que lhe sirva de suporte motivacional para o agir e o pensar.

A vinculação deve ser vista como um processo contínuo em que é importante que os institucionalizados sintam o investimento de figuras afetivamente presentes, o que criará uma segurança emocional que potencia a capacidade de desenvolver estratégias de coping, tornando-os mais confiantes. $\mathrm{O}$ acompanhamento duradouro, contínuo e humanizado por parte dos educadores às crianças institucionalizadas reveste-se de enorme importância no estabelecimento de uma relação de confiança, tantas vezes abalada por sucessivos abandonos anteriores. Eventualmente será a base para uma motivação acrescida, que se reflete em mais empenho e menor absentismo escolar, já que esses adultos podem assumir verdadeiros papéis no sentido de orientá-los, proteger e acarinhar, constituindo inclusivamente os seus modelos identificatórios.

O processo resiliente do jovem sairá reforçado se a relação com as figuras que trabalham na instituição concorrer para uma reorganização interna das vias de vinculação, através de um esforço contínuo no sentido de melhorar a empatia. Uma boa vinculação "produz" pessoas seguras e dispostas a enfrentar as novas situações com uma postura confiante e determinada, características imprescindíveis para uma autonomização de sucesso. Já uma vinculação insegura pode levar os jovens a diligenciarem por uma independência inconsequente como forma de procurar um amparo no sentimento de realização pessoal. Mas a busca de 
emancipação radical patenteia muitas vezes a fragilidade e insegurança dos jovens, incapazes de superar as barreiras de forma adaptativa. Estas defesas afetivas são estratégias na tentativa de evitarem um eventual sofrimento que a total abertura e entrega de si mesmos, na plenitude das suas emoções, podia causar. A opção pelo refúgio no silêncio, insensibilidade, indiferença ou afastamento pode ocorrer, caso não se sintam incondicionalmente aceites e poderá ser encarada como resposta a sentimentos de rejeição e insegurança, podendo agravar-se despoletando raiva, ansiedade, depressão e outros sentimentos de dor.

A institucionalização não representa forçosamente uma transição negativa, pois os laços afetivos mantidos após a autonomização são responsáveis por muitos ex-acolhidos apontarem o período de acolhimento como o melhor das suas vidas por ter potenciado tais relacionamentos. Já as vivências pessoais, emocionais e sociais a que foram expostos podem gerar vulnerabilidades que se agravam face a fatores de risco (Mota \& Matos, 2008). A privação completa de cuidados primários e apoio afetivo pode ter um efeito permanente no desenvolvimento da personalidade e na capacidade de formar, suster e desfrutar das relaçóes (Marrone, 1998).

\section{Estudo das transições}

Segundo Bronfenbrenner, as transições não-normativas (nas quais se incluem eventos inesperados como a entrada para um lar de acolhimento) ou normativas (como a autonomização planeada), são geradoras de mudanças na perceção de si mesmo e dos outros e no estabelecimento de relaçóes.

A Teoria Bioecológica do Desenvolvimento Humano destaca a importância das transiçôes que ocorrem no ambiente ecológico, as chamadas transiçóes ecológicas, consideradas ao mesmo tempo produto e produtor de mudanças no desenvolvimento (Bronfenbrenner, 1979/2004).

Em termos práticos, Schlossberg refere que, fazendo uma leitura dos 4 S's (Situation, Support, Self, Strategies) do indivíduo, é possível delinear a área do problema e acalmar o sofrimento da mudança, modificando essa área (Schlossberg \& Entine, 1997).

Para os jovens adultos em geral, o modelo tradicional de transição, com a sucessão de três fases bem definidas e delimitadas - o trajeto escolar, a entrada no mercado de trabalho, o casamento e saída de casa dos pais (Galland, 1991) parece estar em franca erosão. Se é notório que essas três esferas permanecem essenciais para a esmagadora maioria dos jovens, elas tendem a ser adiadas e deixam cada vez mais de corresponder a três fases claras e bem delimitadas do processo de transição. 
Para os adultos e jovens adultos ex-institucionalizados que se autonomizaram do Lar onde foram acolhidos, um regresso à casa dos pais, por norma, está posto de parte, emergindo antes em novos modelos não-lineares de transição, centrados no risco e na imprevisibilidade, caracterizados por uma sucessão de situações complexas e transitórias, experiências e retrocessos (Pais, 2001; Brannen $\&$ Nilsen, 2002). Por um lado, a entrada no mercado de trabalho nem sempre é consistente e duradoura, por outro, o casamento raramente está associado à saída da instituição, fatores que abrem um campo infinito de oportunidades, combinaçóes e experiências.

Vendo a transição como a resposta humana ao traumatismo e à mudança, os acontecimentos positivos podem demorar até um ano para serem "absorvidos" e os eventos traumáticos entre dois e quatro anos, sendo que para vários autores como (Adams, Hayes, \& Hopson, 1976), podem ser esquematizadas fases e características comuns a transições (ver Figura 2).

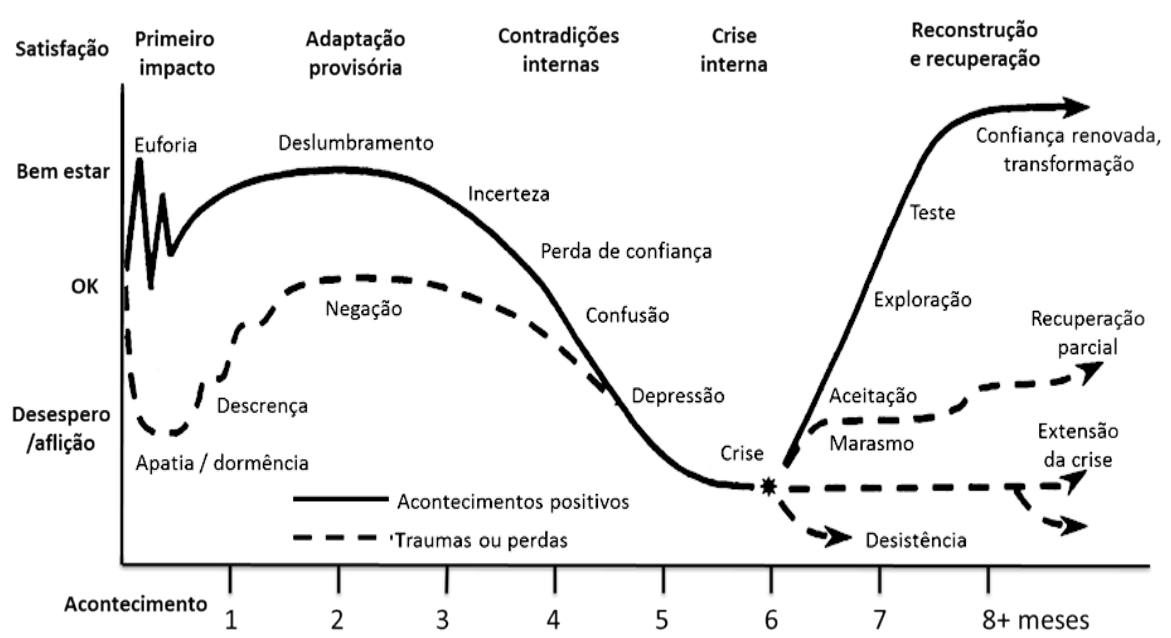

Figura 2. Fases e características da transição, adaptado de Adams, Hayes e Hopson (1976)

$\mathrm{O}$ jovem adulto em processo de autonomização necessita adaptar-se ao traumatismo e mudar, pois os bons eventos, assim como os maus, podem desestabilizar as suas mentes, exigindo alteraçóes na sua compreensão do mundo. Se compreendidas e suportadas, as transiçôes podem ser momentos decisivos e oportunidades, mas, se tal não acontecer, podem conduzir à depressão a longo prazo, à quebra de relacionamentos e de carreiras, ou até ao suicídio. As transi- 
çóes múltiplas podem produzir uma deterioração cumulativa no bem-estar se o indivíduo é incapaz de recuperar-se antes de outra mudança.

Alguns jovens institucionalizados evitam a todo o custo pensar no momento da saída, adiando a tomada de decisóes ou mesmo dar passos nesse sentido, comungando de certo sebastianismo salvador que possa inverter as coisas ou resolvê-las por si mesmo.

A teoria de desenvolvimento psicossocial de Schlossberg indica-nos que a autonomização da instituição onde cresceu constitui um processo de mudança que se reflete em quatro áreas do desenvolvimento do indivíduo - rotinas, papéis, relacionamentos interpessoais e perceção acerca de si e do mundo -, exigindo ao jovem adulto que mobilize diferentes recursos e estratégias.

\section{Metodologia}

A ação passou pelo recurso a entrevistas semiestruturadas ${ }^{2,3}$ a 24 adultos e jovens adultos que viveram em Lares de Infância e Juventude.

Todas as entrevistas começaram por uma componente escrita e os participantes tiveram algumas semanas para refletir e registar à medida que tivessem disponibilidade temporal e emocional ${ }^{4}$.

Após um contato inicial (presencialmente, por telemóvel ou informaticamente), recorreu-se ao correio eletrónico para fazer chegar o guião da entrevista, que após preenchimento foi devolvido pelo mesmo modo. Após a análise das respostas, foram promovidos encontros presenciais para complementar informações e aprofundar algumas perceçóes. Nestes encontros presenciais foi pedido que registassem os momentos de vida mais marcantes (positivos e negativos).

Por manifesta falta de competências para a escrita organizada por parte de alguns entrevistados, o recurso à oralidade presencial prevaleceu claramente sobre os registos escritos. Em casos pontuais, procedeu-se à recolha adicional de informaçóes, junto de irmãos, colegas de trabalho, colegas de curso, colegas de casa, outros ex-utentes e chefias/entidades patronais.

No contato inicial foi abertamente explicada a cada participante a finalidade científica da pesquisa, garantida a confidencialidade, a ausência de dano do processo e o direito de recusa ou interrupção no momento em que desejassem. Após esta contextualização, foi pedido o consentimento informado. A componente gravada das entrevistas foi realizada no local e horário mais adequado a cada participante, tendo início após a permissão para ligar o gravador e lembrado ao entrevistado o destino do material gravado. 
Partiu-se de um universo de cerca de uma centena de jovens adultos que viveram vários anos nos Lares envolvidos no estudo, acabando por serem dirigidas entrevistas a 26 ex-utentes, tendo sido recolhidas apenas 24, por manifesta falta de disponibilidade num caso e alguma instabilidade emocional no outro. A seleção foi feita de modo aleatório, dependendo essencialmente da disponibilidade de cada indivíduo.

Para potenciar a validade holística, defendida por Bronfenbrenner (1979/2004), que ressalta a importância de contrastes ecológicos, incluiu-se um elevado número de características (contextos e variáveis) relacionadas com o fenómeno em estudo, pelo que se levou em consideração a idade à entrada e à saída da instituição, a origem geográfica, o tempo de permanência no Lar, o género, a etnia, ou motivos da institucionalização ou a integração social.

Para assegurar aspetos relacionados com a fidelidade e a validade do estudo, procurou-se assegurar que seria atingida a saturação dos dados ${ }^{5}$, bem como salvaguardar as questôes de ordem ética normalmente levantadas quando são utilizadas amostras muito pequenas e em que trabalhamos com informaçóes verdadeiramente pessoais, por se correr o risco de possível identificação dos informadores e deste modo não cumprir o compromisso de confidencialidade que sabemos ter de respeitar (Guerra, 2006).

Seguindo esta metodologia, os diversos contatos e as entrevistas aos participantes, embora tenham consagrado muito tempo, foram fundamentais para o estudo pois permitiram desenvolver uma aproximação relacional, de observação abrangente e otimizar a etapa metodológica seguinte - sinopse e análise do seu conteúdo.

Vários sujeitos mostraram contentamento por terem participado, chegando mesmo a agradecer por o estudo lhes ter proporcionado uma reflexão profunda sobre o seu passado, as suas vivências e sobre si próprios.

\section{As Instituiçóes em estudo}

Os dois Lares de Infância e Juventude (LIJ) intervenientes neste estudo, embora com os mesmos corpos sociais, apresentam realidades distintas, desde logo pela disparidade na localização geográfica e espaços físicos, diferente visibilidade pública e presença de entidades, diversidade nos vínculos e relacionamentos peculiares de cada casa, fruto em grande parte dos caracteres pessoais dos recursos humanos que lá trabalham e principalmente do público-alvo, além de outros aspetos como a figura do diretor técnico ou da encarregada geral, que ajudam a conferir a cada Lar uma entidade própria. 
Ambos os Lares operam em regime aberto, de acordo com as normas gerais de funcionamento constantes no regulamento interno de cada equipamento, ou de acordo com as deliberaçóes das entidades oficiais com competência na matéria de infância e juventude.

Cada Lar tem um quadro de funcionários que assegura o funcionamento dos serviços prestados, visando colmatar as necessidades educativas, de animação e ocupação de tempos livres, bem como as questões de natureza psicossocial. É constituído por técnicos de serviço social, psicólogos, professores, monitores e auxiliares de ação educativa, além de funcionários que asseguram a alimentação, higiene, transportes e área administrativa ${ }^{6}$.

O Lar que funciona como sede de toda a Obra foi fundado em 1973, tendo o outro sido aberto oito anos mais tarde. As duas instituiçóes funcionam permanentemente, durante as 24 horas do dia, em todos os dias do ano. No entanto, durante o fim de semana e período noturno, no qual a presença dos acolhidos é mais constante, verifica-se uma quase ausência de professores, técnicos e encarregada geral.

Os dois LIJ em estudo acolhem crianças e jovens de ambos os sexos, sendo que atualmente um recebe menores ${ }^{7}$ com doze ou mais anos, colocados por Acordo de Promoção e Proteção ou Decisão Judicial, tendo uma população (março de 2012) constituída por 20 menores de ambos os sexos, enquanto o outro se dirige a crianças entre os seis e os doze anos, tendo 26 acolhidos. Em ambos há um baixo índice de menores por cuidador.

\section{Caracterização dos intervenientes, resultados e sua discussão}

A caracterização dos jovens adultos intervenientes neste estudo encontra-se no Quadro A a seguir, no qual a idade de entrada, duração do acolhimento e idade de autonomização são analisados.

O tratamento dos dados baseou-se na análise do conteúdo das entrevistas, procurando efetuar inferências sobre as mensagens cujas características foram inventariadas e sistematizadas (Vala, 1986). A natureza exploratória do estudo privilegiou a análise de conteúdo conduzida indutivamente, perspetivando a produção de descoberta a partir dos significados expressos pelos sujeitos.

$\mathrm{O}$ processamento da informação foi feito inicialmente com recurso ao webQDA para tratamento e categorização dos dados, mas o tamanho da amostra, e sobretudo da informação, criou dificuldades de operacionalização. 


\section{Quadro A}

\section{Período de institucionalizaçáo}

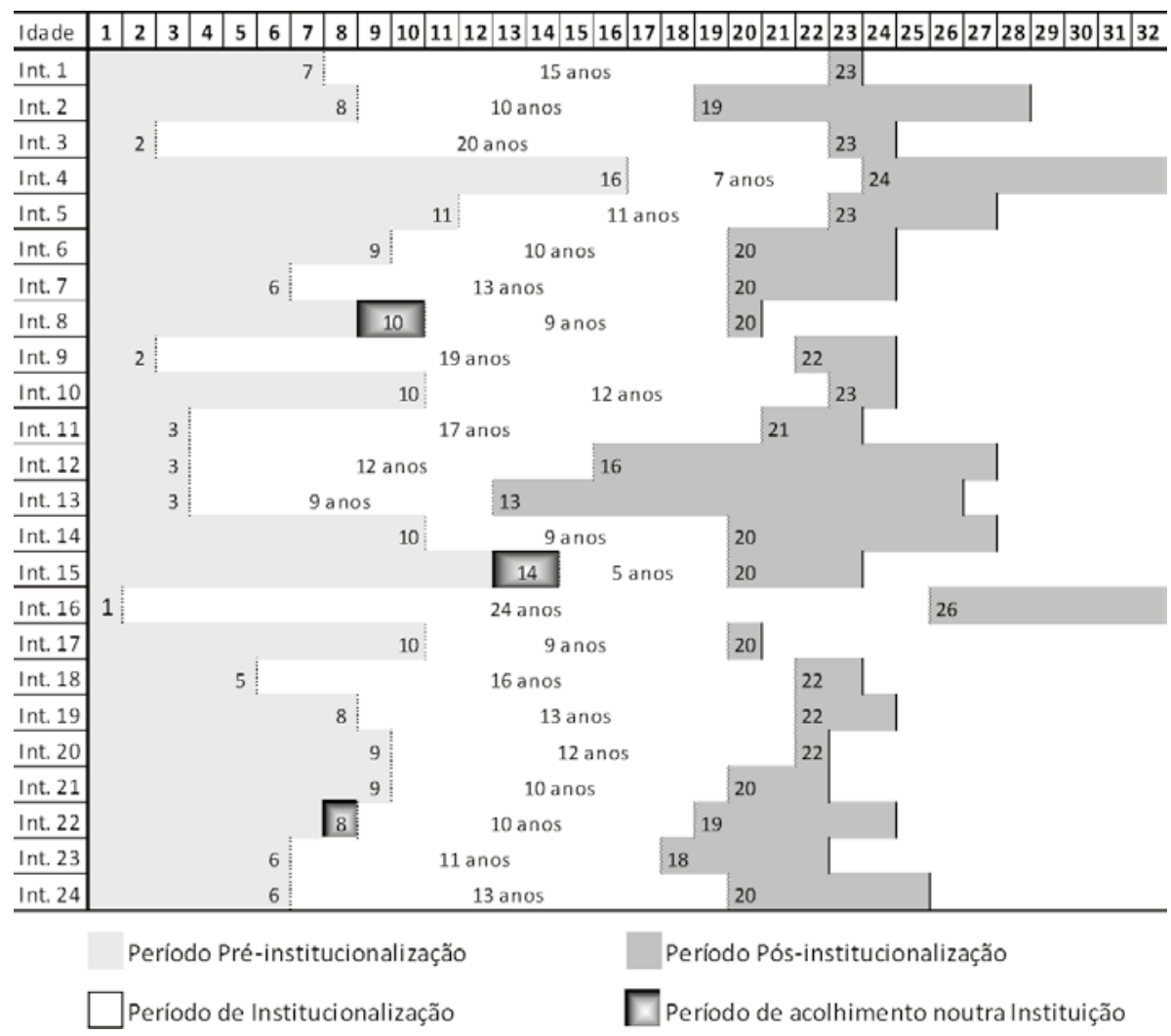

Caracterizaçáo dos jovens adultos intervenientes. Os períodos de institucionalização oscilaram entre os 5 e os 24 anos, tendo a amostra uma média superior aos 12 anos. São raros os intervenientes que entram para acolhimento após os 10 anos, assim como apenas dois os que saem antes dos 18 anos.

Foi entáo realizada uma análise narrativa sem contagem de ocorrências, embora salientando as categorias mais comuns, apenas enfatizando as menos representativas quando tal se mostrar teoricamente relevante.

Valorizou-se portanto a função heurística, desvendando o sentido do conteúdo, aumentando a propensão à descoberta (Bardin, 1977), tentando interpretar a relação entre o sentido subjetivo da ação, o ato objetivo e o contexto social em que decorrem as práticas em análise (Guerra, 2006). 
Da análise dos momentos de vida marcantes claramente surgem a entrada para a institucionalizaçấo e a saída desta como os mais negativos. Os desgostos amorosos e a perda de familiares também surgem nos aspetos negativos, mas com menor recorrência.

Já nos momentos positivos houve alguma dificuldade em elegerem os mais importantes, mas sempre destacando algumas referências à entrada para o ensino superior, ou mesmo sucessos desportivos.

O momento do acolhimento surge quase invariavelmente como doloroso, associado a pouco envolvimento de quem recebe e a um corte com a família.
"Não gostei. Passei muitos dias a chorar" (Interveniente 2). "O primeiro dia foi péssimo, não conhecia ninguém" (Interveniente 6). "Lembro-me como se fosse hoje, [...] fiquei naquela casa grande com gente desconhe- cida que me metia medo e que não me transmitia a calma da minha mãe. Foi horrível aquele momento!" ( Interveniente 1).

Os jovens adultos em estudo percecionaram o momento do acolhimento negativamente, sobretudo pela associação à separação da família e à entrada num meio desconhecido. A afetividade mostrou-se importante na forma como entenderam positiva ou negativamente a receção no lar, sendo a presença e atitude carinhosa dos pares e recursos humanos da instituição relevante para promover transiçôes mais favoráveis num momento tão marcante.

A maioria dos intervenientes não recorda a pessoa (diretor, técnico ou funcionária) que o acolheu, mas todos consideram importante o primeiro contato, chegando a dizer que a primeira noite foi pior por não terem qualquer referência na instituição, nenhum cuidador a dar carinho e a tranquilizar no momento de adormecer. Não se verifica um protocolo de integração nos lares estudados, embora logo no momento do acolhimento a dimensão afetiva deva ser encarada como componente essencial, constituindo o suporte de uma transição intensa, sendo uma oportunidade para as instituiçôes valorizarem desde o início o afeto nas relaçóes entre a população juvenil e entre esta e os seus cuidadores.

Sobre o relacionamento entre os pares, unanimemente consideraram as relaçóes positivas, sendo que a maioria perceciona essas interaçóes como marcantes e significativas para a sua estabilidade emocional, suprindo algumas lacunas relacionais com adultos.

\footnotetext{
"Era uma relação de fraternidade, criaram-se laços importantes, pessoas pelas quais tenho a maior consideração. Pessoas com quem passei o mais
} 
longo e melhor momento da minha vida. Era raro haver atritos relevantes entre utentes. Foi como ganhar uma nova família e novos irmãos" (Int. 10) "Era uma relação muito boa, praticamente como irmãos, ainda hoje permaneço com grandes amizades vindas da instituição" (Int. 9).

Os lares de infância e juventude representam o microssistema em que os menores acolhidos realizam atividades e desenvolvem interaçóes, o que o torna um ambiente ecológico capaz de potenciar o desenvolvimento de relaçóes recíprocas, de equilíbrio de poder e de afeto. Segundo Martins \& Szymanski (2004), as crianças institucionalizadas apresentaram comportamentos pró-sociais e de ajuda recíproca, sendo as relaçóes estabelecidas entre os pares o aspeto positivo mais referido pelos intervenientes.

Esses lares em análise proporcionaram relaçóes entre os pares satisfatórias e capazes de deixarem marcas muito positivas e que se prolongam no tempo. As recordações são de tal forma favoráveis que à luz da Teoria Ecológica do Desenvolvimento Humano podem ser enfatizadas, relegando os aspetos negativos encontrados, quando comparados com crianças e adolescentes que se desenvolvem em contextos culturalmente esperados. Estes laços foram indicados por alguns intervenientes como contributos importantes para aumentar a resiliência e a capacidade de vivenciar transiçóes ao longo da vida, chegando, em muitos casos, crianças e adolescentes a tratarem-se como "irmãos".

Relativamente à apreciação que os jovens em estudo fazem da vida relacional com os adultos da instituição, surgem sentimentos perfeitamente antagónicos. Para muitos a maioria dos cuidadores revelou pouca vocação e empenho para os cargos que desempenhava, embora reconhecessem grande valia a alguns.

\footnotetext{
"A relação dos funcionários com os utentes pode-se dividir em duas ideias diferentes, havia os funcionários que trabalhavam apenas porque era o seu emprego e havia aqueles funcionários que para além de ser o emprego eram um porto para ajudar crianças necessitadas de carinho, de amor, de tudo o que não encontraram numa família [...] também posso dizer que estes foram os tais que me fizeram crescer e me deram educação, ideias, ajudaram a formar a minha pessoa, a pessoa que sou hoje" (Int. 3). "A relação era boa com alguns e péssima com outros, havia ali pessoas que não tinham formação pessoal para lidar com alguns dos jovens, não tinham forma de falar, forma de estar" (Int. 24).
}

Embora as perceçóes sejam geralmente desfavoráveis, ressalvam alguns adultos que têm como referência, mostrando gratidão pela entrega e dedicação. 
"Era uma pessoa muito culta, tinha uma paciência do tamanho do mundo fazia de tudo para nós estarmos bem” (Int. 7). "ela recebeu-me como uma filha, tirava-me as espinhas do peixe, cortava-me a carne, dava-me mimos, abraçava-me fortemente antes de ir para casa" (Int. 1). "Foi um grande anjo da guarda porque sempre me ajudou e a todos os utentes, em grandes momentos das nossas vidas" (Int. 9).

Quase todos os intervenientes conseguem indicar algum cuidador que os marcou negativamente, chegando a considerá-lo como fator saliente no seu período de acolhimento.

"Uma psicóloga porque ia contra tudo o que é a ética da sua profissão [...] pessoa mesquinha, mal dizente, cínica e falsa" (Int. 2). "Uma funcionária da lavandaria, era muito agressiva e chegava a bater sem motivo nenhum. Ainda hoje quando me lembro, tenho a sensação de sentir os dedos dela na minha cara" (Int. 18).

A perceção de vários intervenientes relativamente aos técnicos incide na incompetência, distanciamento e pouco humanismo.

“já com os técnicos era totalmente o contrário, não apareciam, quando apareciam era apenas em reuniôes, apenas para chamar à atenção e muitas das vezes de coisas que não sabiam ao certo, mas agora vejo por que é que não sabiam, porque simplesmente não viviam nada ali dentro, não partilhavam momentos, logo não saberiam lidar com certas situações” (Int. 20). "A relação não era das melhores, pouca empatia, pouco dignos de confiança, muito 'a leste' do que vivíamos e do que sentíamos” (Int. 8).

Do momento da saída da instituição, registamos sentimentos contraditórios, que passam pela libertação das regras da instituição e pelo receio de solidão e abandono. Embora vários jovens mostrem sentimentos de nostalgia, revelando saudades extremas, o momento da saída não é recordado com alegria, registando-se perceçóes de banalização e pouco cuidado com um dia tão marcante para os jovens.

"Senti-me um pouco confuso e desamparado" (Int. 11). "Alívio, sentimento de liberdade, revolta, tristeza [...]" (Int. 4). "Uma enorme tristeza, parecia que a vida tinha chegado ao fim" (Int. 21). "Fiquei feliz por finalmente 
sair e triste por deixar todos para trás, lembro-me de chorar alguns dias seguidos e ter vontade de voltar" (Int. 13). "Na altura fiquei feliz, mas passado um mês já queria voltar" (Int. 23). "É difícil descrever, pois senti uma enorme tristeza ter que deixar a que foi minha casa durante uma vida, não queria ter que deixar para trás quem me criou, viu crescer, rir, chorar. É muito difícil é como ter de deixar toda uma vida que criamos em anos, num dia" (Int. 16). "Peguei nas minhas coisas, sozinha e apenas uma pessoa que lá trabalhava se despediu de mim. Foi mau” (Int. 12).

A preparação da saída da instituição praticamente não se verificou, embora os intervenientes tenham atribuído um forte pendor ao plano relacional no momento da saída. A ausência de um protocolo de despedida não facilita o impacto desta ocorrência, deixando nos jovens uma sensação de vazio e mesmo de desinteresse por parte dos cuidadores.

Trata-se claramente de um momento marcante, uma transição que não é favorecida por um suporte adequado, ou um contexto facilitador.

Sobre o apoio que tiveram da parte dos Lares após a saída, a análise dos sentimentos dos jovens adultos revela raiva pelo abandono a que foram votados, não compreendendo como tal foi possível, da parte de quem cuidou deles durante tantos anos.

"A partir desse ponto não recebi qualquer apoio da instituição" (Int. 10). "Sair da casa onde viveste grande parte da tua vida sem qualquer apoio financeiro é um suicídio" (Int. 15). "Aí não senti apoio de ninguém e até hoje não tive ninguém que me ligasse para saber como estou, como me encontro, se preciso de apoio, nada” (Int. 3).

Neste aspeto é perfeitamente notória a distinção que fazem pela negativa dos técnicos relativamente a outros cuidadores, nomeadamente professores.

"Da parte das técnicas não recebi apoio nenhum, muito pelo contrário, azucrinaram-me a cabeça até aos meus últimos dias no lar e até nos momentos mais importantes da minha vida, fingiam não me conhecer" (Int. 18) “Tive sim sempre alguém a olhar por mim, a estar lá quando eu precisei e não precisei, com apoio incondicional [...]. As pessoas que realmente fazem algo para o melhor das crianças ali [...] apenas e sempre os professores. Mais ninguém, muito menos os técnicos” (Int. 23). 
De uma maneira geral, ocorre uma rutura com a instituição, não só com o espaço físico, onde sentem que não são bem-vindos, mas também nos contatos com os técnicos, havendo um "apagar" forçado do lar onde cresceram e a que carinhosamente chamam "casinha”.

A continuidade que uma perspetiva ecológica sugere mostra que o desenvolvimento destes jovens é afetado pelas vivências com outras figuras significativas que deviam dar respostas pessoais, afetivas e sociais, potenciando a sua adaptação à autonomização. De entre estas figuras apontamos a relação com os pares, os professores e, em casos pontuais, outros funcionários como as únicas pessoas com interesse pela pessoa, ainda que já não faça parte da comunidade, contribuindo para que os jovens se sintam mais seguros, ficando também receptivos a possíveis ligações futuras. A identificação afetiva prolongada após a saída do Lar com essas figuras é relevante para a contribuição da escolha das trajetórias de vida.

\section{Conclusóes e implicaçóes para a intervenção}

A abordagem fenomenológica que esteve na base desta pesquisa tornou notória a perceção que os intervenientes têm do corte abrupto com o meio familiar e social de origem aquando da entrada no Lar de acolhimento e do "desaparecimento" da instituição após a sua saída. Relativamente às transiçóes, podemos concluir que os intervenientes entendem a institucionalização como uma descontinuidade de importância extrema, fazendo uma clara distinção nos períodos antes, durante e após o seu acolhimento.

Com base na perspetiva de Schlossberge, Waters e Goodman (1995), é fundamental que a instituição crie mecanismos de suporte na transição que corresponde ao acolhimento e de apoio na fase de saída dos Lares. Assim, os jovens adultos desenvolverão mecanismos de resposta que visem permitir uma adaptação às novas etapas da sua vida.

O envolvimento de médio/longo prazo potenciou a riqueza dos dados, proporcionando uma análise narrativa e sequencial e permitindo concluir que, nos Lares em estudo, os intervenientes praticamente não encontraram relaçóes afetivas significativas e securizantes, sobressaindo as relações de quase indiferença ou mesmo ruturas e perdas sucessivas, o que reforça as teorias sobre vinculação em análise.

Os jovens adultos relatam pouco investimento pessoal dos recursos humanos, nomeadamente dos técnicos das instituiçóes em estudo, assumindo que, além de distantes, não teriam as características pessoais e profissionais adequadas à função desempenhada. 
A investigação desenvolveu-se de acordo com as teorias já existentes, mostrando que é importante criar mecanismos que aumentem a vinculação, fomentando interaçóes proximais positivas (microssistema), favorecendo o suporte nas transições ocorridas ao longo da vida, potenciando maior resiliência e consequente integração social nos jovens que viveram vários anos acolhidos em lares de infância e juventude (Figura 3).

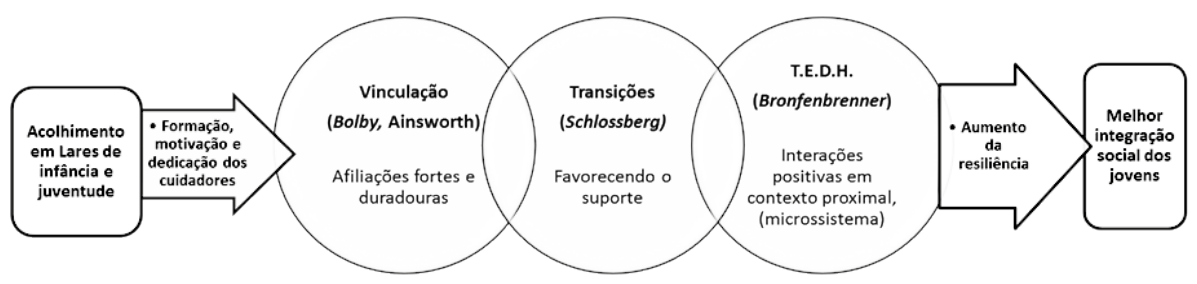

Figura 3. Esquema síntese das conclusōes

$\mathrm{Na}$ entrada para as instituiçóes, é necessário que se minimize o impacto inicial recorrendo a todas as estratégias, dependendo de fatores como a idade de acolhimento, da existência de frateria ou do apoio familiar.

Na saída, os jovens adultos deverão pensar, calcular e ativar os seus recursos para promoverem um ajustamento positivo a um novo contexto, com autonomia e responsabilidade. À luz da teoria ecológica do desenvolvimento humano o microssistema e o mesossistema assumem-se como os contextos mais importantes e que poderão ter um papel mais relevante na integração. De acordo com a perceção dos intervenientes, as afiliaçóes desenvolvidas antes, mas sobretudo no período de institucionalização, foram determinantes como interaçóes seguras, tendo influência no entendimento positivo ou negativo que fazem das transiçóes que já vivenciaram e na preparação para a vida adulta. Nas suas perspetivas de adultos e jovens adultos, enquanto menores institucionalizados, não só estão disponíveis para estabelecer ligações afetivas como, quando recebem carinho, atenção e cuidado, também sabem demonstrar interesse e retribuir, estando ávidos de relacionamentos estáveis e recíprocos.

Muitas melhorias no acolhimento de crianças e jovens em risco dependem de boas práticas institucionais, importantes para o sucesso nas transiçóes ao longo da vida das crianças e jovens acolhidos que, com base nos resultados deste estudo $^{8}$, em opinióes de vários autores e também na experiência acumulada, serão proximamente objeto de investigação.

Para mais e melhor entendimento sobre estas questóes, sugere-se que o estudo possa ser ampliado e replicado, abrangendo mais ex-institucionalizados ${ }^{9} \mathrm{e}$ 
mais LIJ, eventualmente privilegiando a hermenêutica, pois entende-se que o conhecimento sobre a problemática em estudo tem muito a ganhar com a utilização de metodologias qualitativas por estas darem conta das experiências analisadas, contrastando com uma análise inferencial, que não permite dissecar a interpretação que os próprios participantes têm da situação em análise.

\section{Referências}

Adams, J., Hayes, J., \& Hopson, B. (1976). Transition: understanding and managing personal change. London: Martin Robinson.

Ainsworth, M. (1977). Attachment theory and its utility in cross-cultural research. In $\mathrm{H}$. Leiderman, S. Tulkin, \& A. Rosenfield (Eds.), Culture and infancy (pp. 15-27). New York: Academic Press.

Ainsworth, M. (1989). Attachments beyond infancy. American Psychologist, 44(4), 709-716.

Bardin, L. (1977). Análise de conteúdo. Lisboa: Edições 70.

Bowlby, J. (1969). Attachment and Loss, v. 1: Attachment. New York: Basic Books.

Brannen, J., Nielsen, A. (2002).Young people's time perspectives: from youth to adulthood. Sociology - British Sociological Association, 36(3), 513-537.

Bronfenbrenner, U. (2004). Making human beings human: biecological perspectives on human development. Londres: Sage. (Trabalho original publicado em 1979)

Bronfenbrenner, U., \& Morris, P. (1998). The ecology of developmental processes. In W. Damon (Ed.), Handbook of child psychology, v. 1 (pp. 993-1028). New York: John Wiley \& Sons.

Galland, O. (1991). Sociologie de la jeunesse: l'entrée dans la vie. Paris: Armand Colin.

Guerra, I. (2006). Pesquisa qualitativa e análise de conteúdo: sentidos e formas de uso. Estoril: Principia.

Gaspar, J. P. (2013). Do acolhimento à autonomização: o que dizem adultos que viveram institucionalizados. Breves notas metodológicas. Revista Eletrônica Polêm!ca, 12(1), 7-22.

Marrone, M. (1998). Attachment and interaction. London: Jessica Kingsley Publishers.

Martins, E., \& Szymanski, H. (2004). A abordagem ecológica de Urie Bronfenbrenner em Estudos com famílias. Estudos e Pesquisa em Psicologia, 1, 66-77.

Mota, C., \& Matos, P. (2008). Adolescência e institucionalização numa perspetiva de vinculação. Psicologia e Sociedade, 20(3), 367-377.

Pais, J. (2001). Ganchos, tachos e biscates: jovens, trabalho e futuro. Porto: Ambar.

Pereira, M., Soares, I., Dias, P., Silva, J., Marques, S., \& Baptista, J. (2010). Desenvolvimento, psicopatologia e apego: estudo exploratório com crianças institucionalizadas e suas cuidadoras. Psicologia: Reflexão e Crítica, 23(2). Recuperado em 7 jan. 2011, de <http://www.scielo. br/scielo.php?script=sci_arttext\&pid=S0102-79722010000200004\&lng=pt\&nrm=iso $\geq$. 
Rousseau, N., \& Saillant, F. (2003). Abordagens de investigação qualitativa. In M. Fortin (Ed.), O processo de investigação: da conceção à realização (pp. 147-160). Loures: Lusociência. Schlossberg, N., \& Entine, A. (1997). Counseling adults. California: Brooks/Cole Publishing Company.

Schlossberg, N., Waters, E., \& Goodman, J. (1995). Counseling adults in transition. New York: Springer.

Strecht, P. (1998). Crescer vazio: repercussões psíquicas do abandono, negligência e maus tratos em crianças e adolescentes. Lisboa: Assírio e Alvim.

Vala, J. (1986). A análise de conteúdo. In A. Silva, \& J. Pinto (Eds.), Metodologia das Ciências Sociais (pp. 101-128). Porto: Afrontamento.

Yunes, M., Miranda, A., Cuello, S. (2004). Um olhar ecológico para os riscos e as oportunidades de desenvolvimento de crianças e adolescentes institucionalizados. In S. H. Koller (Ed.), Ecologia do desenvolvimento humano: pesquisa e intervençōes no Brasil (pp.197-218). São Paulo: Casa do Psicólogo.

\section{Notas}

${ }^{1} \mathrm{O}$ presente artigo decorre do trabalho desenvolvido no âmbito do Doutoramento em Ciências da Educação, na área de especialização em Psicologia da Educação, na FPCE da Universidade de Coimbra.

${ }^{2}$ Realizou-se um estudo piloto a dois ex-acolhidos (que não entraram na amostra final), no sentido de aferir eventuais lacunas e aperfeiçoar, tentando aumentar a credibilidade das questôes qualitativas.

${ }^{3}$ Guião em <http://www.slideshare.net/pedritoportugal $>$.

${ }^{4}$ Os trabalhos de recolha decorreram entre setembro/2011 e março/2012, com especial aproveitamento da época natalícia, pois os participantes vivem em todo o país e na Europa.

${ }^{5}$ De acordo com Rousseau e Saillant, a ideia da saturação dos dados "faz referência ao momento da colheita de dados a partir do qual o investigador não aprende nada de novo dos participantes ou das situaçóes observadas" (Rousseau e Saillant, 2003).

${ }^{6}$ Há uma tendência para prolongar a manutenção das mesmas pessoas nos cargos, sendo que a maioria dos funcionários já trabalha na instituição há mais de duas décadas, sendo esporádicas as alteraçóes ao quadro de pessoal.

${ }^{7}$ Sem querer fazer menção às críticas da ideia de "menoridade" que a promulgação do Estatuto da Criança e do Adolescente, no Brasil, procurou superar, mas consciente do sentido pejorativo do termo, fica apenas uma reflexão: "Menor é o Outro assustador dentro da criança e na criança, estragando a imagem de inocência e pureza ainda" (Maia, Zamora, Vilhena, \& Bittencourt, 2007). 
${ }^{8}$ Desde logo a ausência de técnicos e professores ao fim de semana e período noturno (pós hora de jantar), pois seriam tempos de maior disponibilidade por parte dos acolhidos e eventualmente aproveitados para desenvolver vinculaçóes. No fundo, como as famílias fazem, aproveitando esses momentos para lazer educativo.

${ }^{9}$ Propositadamente neste artigo não foi utilizada a palavra "utentes", terminologia usada sistematicamente nas instituiçóes em estudo, pois muitos dos menores acolhidos reside mais de uma dezena de anos nos Lares. Por isso, a expressão "residentes" parece mais adequada para designar os jovens que lá vivem.

DOI: $10.1590 / 0103-56652015000100004$ 


\section{Anexo \\ Causas da institucionalização e agregado familiar antes e depois do acolhimento}

\begin{tabular}{|c|c|c|c|c|c|c|c|c|c|c|c|c|c|c|c|c|c|}
\hline & \multicolumn{8}{|c|}{ Motivo da institucionalização } & \multicolumn{4}{|c|}{ Com quem vivia } & \multicolumn{5}{|c|}{ Com quem vive } \\
\hline & 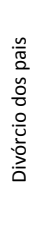 & 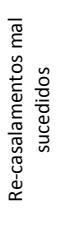 & 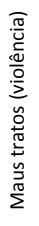 & 党 & 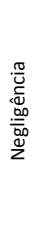 & 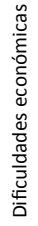 & 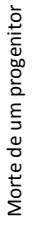 & 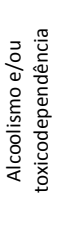 & 号 & 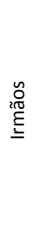 & $\sum^{2 \pi}$ & $\bar{\pi}$ & $\begin{array}{l}\stackrel{\text { Uू }}{2 \pi 0} \\
\underline{\underline{20}}\end{array}$ & 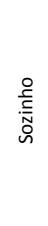 & 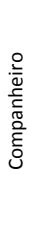 & 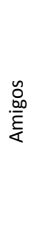 & $\sum_{2 \pi}^{2 \pi}$ \\
\hline $\operatorname{Int} 1$ & & & & $\checkmark$ & & $\checkmark$ & & & & $\checkmark$ & $\checkmark$ & & & $\checkmark$ & & & \\
\hline Int.2 & & & & & & & $\checkmark$ & $\checkmark$ & & $\checkmark$ & & $\checkmark$ & $\checkmark$ & & & & \\
\hline Int.3 & & & & & $\checkmark$ & $\checkmark$ & & $\checkmark$ & & $\checkmark$ & $\checkmark$ & $\sqrt{ }$ & & & & $\checkmark$ & \\
\hline Int.4 & & & & & & $\checkmark$ & $\checkmark$ & $\checkmark$ & $\checkmark$ & $\checkmark$ & & & & $\checkmark$ & & & \\
\hline Int.5 & & & & & $\checkmark$ & & & $\checkmark$ & & $\checkmark$ & $\checkmark$ & & & $\checkmark$ & & & \\
\hline Int.6 & & & & & $\checkmark$ & $\checkmark$ & $\checkmark$ & $\checkmark$ & $\checkmark$ & $\checkmark$ & & & $\checkmark$ & & & & \\
\hline Int.7 & $\checkmark$ & $\sqrt{\checkmark}$ & & & & $\checkmark$ & & & & $\checkmark$ & $\checkmark$ & & & & $\checkmark$ & & \\
\hline Int.8 & & $\checkmark$ & & & & $\checkmark$ & & & & $\checkmark$ & $\checkmark$ & & $\checkmark$ & & $\checkmark$ & & \\
\hline Int.9 & & & & & $\checkmark$ & $\checkmark$ & $\checkmark$ & $\checkmark$ & & $\checkmark$ & $\checkmark$ & $\checkmark$ & & & & $\checkmark$ & \\
\hline Int.10 & & & & $\checkmark$ & & $\checkmark$ & & & & $\checkmark$ & $\checkmark$ & & & $\checkmark$ & & & \\
\hline Int.11 & & & & & & & $\checkmark$ & $\checkmark$ & $\checkmark$ & $\checkmark$ & & $\checkmark$ & $\checkmark$ & & & & \\
\hline Int.12 & $\checkmark$ & $\checkmark$ & & & $\checkmark$ & $\checkmark$ & & & & $\checkmark$ & 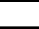 & $\checkmark$ & $\checkmark$ & & & & \\
\hline Int.13 & & & $\checkmark$ & & & & & $\checkmark$ & & & $\checkmark$ & & & & $\checkmark$ & & \\
\hline Int.14 & $\sqrt{ }$ & $\checkmark$ & & & & $\checkmark$ & & & & $\checkmark$ & $\checkmark$ & & & & $\checkmark$ & & \\
\hline Int.15 & $\checkmark$ & $\checkmark$ & & & & $\checkmark$ & & & & $\checkmark$ & $\checkmark$ & & $\checkmark$ & & & & \\
\hline Int.16 & & & & & $\checkmark$ & $\checkmark$ & & & & $\checkmark$ & $\checkmark$ & $\checkmark$ & & & $\checkmark$ & & \\
\hline Int.17 & $\checkmark$ & $\checkmark$ & & & $\checkmark$ & & & & $\checkmark$ & & & & & $\checkmark$ & & & \\
\hline Int.18 & & & & & & $\checkmark$ & & & & & $\checkmark$ & & & $\checkmark$ & & & \\
\hline Int.19 & $\checkmark$ & & & & & $\checkmark$ & & & & $\checkmark$ & $\checkmark$ & $\checkmark$ & & $\checkmark$ & & & \\
\hline Int.20 & & & & $\checkmark$ & & $\checkmark$ & & & & $\checkmark$ & $\checkmark$ & & & $\checkmark$ & & & \\
\hline Int.21 & & & & $\checkmark$ & & $\checkmark$ & & & & $\checkmark$ & $\checkmark$ & & $\checkmark$ & & & & $\checkmark$ \\
\hline Int.22 & & $\checkmark$ & & & & $\checkmark$ & & & & & & $\checkmark$ & & $\checkmark$ & & & \\
\hline Int. 23 & & & & & & & & $\checkmark$ & $\checkmark$ & & & $\checkmark$ & & & & & $\checkmark$ \\
\hline Int. 24 & $\checkmark$ & & $\checkmark$ & & & $\checkmark$ & & & & $\checkmark$ & $\checkmark$ & & & & & & $\checkmark$ \\
\hline
\end{tabular}

Causas da institucionalizaçáo e agregado familiar antes e depois do acolhimento. As dificuldades económicas são claramente as causas mais apontadas, em oposição aos maus tratos. Após o acolhimento, nenhum interveniente vive com o pai, avôs ou outros familiares (que não mãe e irmãos), sendo igualmente de realçar que apenas um interveniente neste estudo tem filhos (dois).

Recebido em 23 de março de 2013 Aceito para publicação em 11 de abril de 2013 
